\title{
THE OCCURRENCE OF HYDROXYINDOLE-O- METHYLTRANSFERASE ACTIVITY IN FETAL SHEEP PINEAL TISSUE AND ITS RELATIONSHIP TO PREPARTURIENT ENDOCRINE CHANGES
}

\author{
D. J. KENNAWAY AND R. F. SEAMARK \\ Department of Obstetrics and Gynaecology, \\ University of Adelaide, South Australia 5001
}

(Received 18th April 1975)

The key role of the fetus in the endocrine changes preceding parturition in the sheep is now well established. Liggins et al. (1974) have shown that the complex series of events which result in parturition are initiated by the fetal hypothalamus. As yet, however, the factors which activate the hypothalamus itself are not known. In the adult, the pineal gland has been shown by many workers to exert an important modifying influence on the function of the hypothalamopituitary system (see Reiter, 1973) and the possible involvement of the pineal at parturition must be considered.

Among the substances which mediate the endocrine functions of the pineal gland are the methoxyindoles melatonin and 5-methoxytryptophol. Present methods for measurement of these hormones in body tissues and fluids are, however, unsatisfactory and most assessments of pineal function are based on the determination of tissue activity of hydroxyindole-O-methyltransferase (HIOMT, EG 2.1.1.4), a key enzyme in their biosynthesis (Urry et al., 1972; Hyyppa et al., 1973).

As part of a study of the role of the fetal pineal, the HIOMT activity in pineal glands of fetal sheep has been determined throughout gestation and the first few days of neonatal life.

Pineal glands from fetal and adult sheep of mixed breeds (mainly Merino cross) were obtained from the local metropolitan abbatoirs (SAMCOR) or from our own flocks. The gestation length in these sheep is 147-150 days. Tissues from animals slaughtered between 09.00 and 13.00 hours only were used. Fetuses were obtained $20-40 \mathrm{~min}$ after maternal death. After weighing of the fetus, a $20-\mathrm{ml}$ blood sample was collected by cardiac puncture, and the pineal gland and other organs removed. The pineal glands were immediately frozen on solid $\mathrm{CO}_{2}$ and assayed within $24 \mathrm{hr}$. In those animals for which the day of mating was unknown, the gestational age was estimated from crownrump length, body weight, and weights of the other organs such as kidneys and testis, from nomograms based on data accumulated in this laboratory.

Activity of HIOMT was assayed by the method of Axelrod et al. (1965). Melatonin was confirmed as the radioactive product by thin-layer chromatography in several solvent systems (Ebels et al., 1972). Under these assay con- 


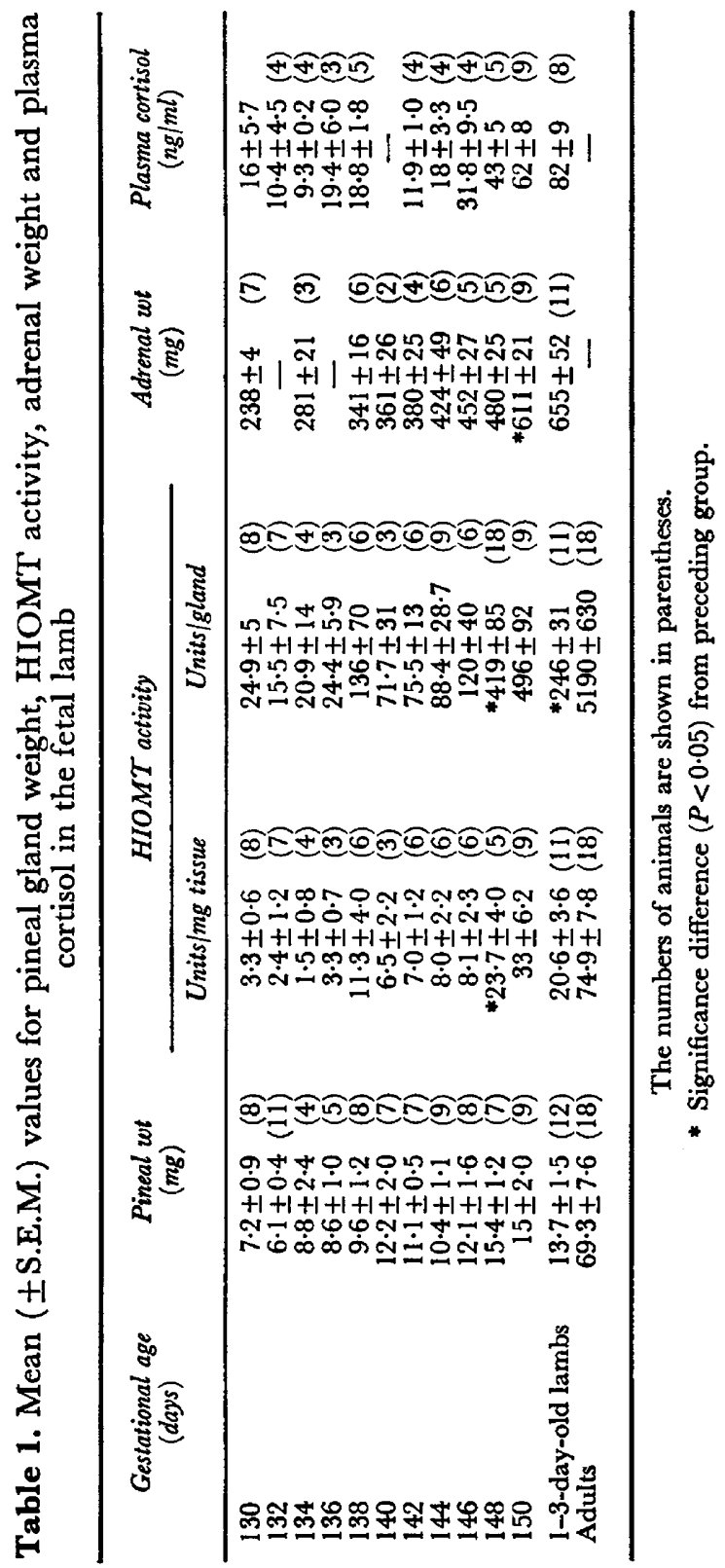


ditions, it was found that production of melatonin was linearly related to substrate concentration, tissue concentration and time up to $60 \mathrm{~min}$. The withinassay coefficient of variation was $9.8 \%$ and the between-assay variation was $7.8 \%$. The HIOMT activity was expressed as units for which 1 unit $=1$ pmol $\left[{ }^{14} \mathrm{C}\right]$ melatonin formed in $60 \mathrm{~min}$ at $37^{\circ} \mathrm{C}$. Plasma cortisol was measured by the competitive protein-binding method of Bassett \& Hinks (1969) and expressed as $\mathrm{ng} / \mathrm{ml}$ plasma. Student's $t$ test was used to evaluate the data.

Table 1 shows the ontogeny of HIOMT activity in relation to pineal and fetal adrenal weight and plasma cortisol. The weight of the pineal gland in the fetal sheep increased linearly with age from approximately $1 \mathrm{mg}$ at 100 days gestation to about $20 \%$ adult size at term. There was no obvious sex difference in the pineal weight. Some pigmentation of the gland was observed but this was not related to size or HIOMT activity, and did not appear to decline with increased gestational age as suggested by Jordan (1911). The sudden rise in HIOMT activity in the last 4-5 days of pregnancy coincides with the period of rapid endocrine change associated with parturition (Comline \& Silver, 1961; Liggins et al., 1974). The change in plasma cortisol seen relates to these changes. In view of the recent evidence concerning the role of the pineal gland in hypothalamic regulation, it is interesting to speculate that changes in fetal pinealhypothalamic-pituitary-adrenal interactions may induce parturition in sheep. Further work is however required to determine the exact temporal relationship between events and to discover if the increase in pineal HIOMT and presumptive release of methoxyindoles is obligatory in the parturition process.

We gratefully acknowledge the assistance given by SAMCOR in providing the biological material used in this study. One of us (D.J.K.) is supported by the Sir John Gellibrand Memorial Scholarship.

\section{REFERENCES}

Axelrod, J., Wurtman, R.J. \& SNyder, S.H. (1965) Control of hydroxyindole-O-methyltransferase activity in the rat pineal gland by environmental lighting. $\mathcal{F}$. biol. Chem. 240, 949-954.

BAsseTT, J.M. \& Hinks, N.T. (1969) Micro-determinations of corticosteroids in ovine peripheral plasma: effects of venipuncture, corticotrophin, insulin and glucose. F. Endocr. 44, 387-403.

Combine, R. \& Silver, M. (1961) The release of adrenaline and noradrenaline from the adrenal glands of the foetal sheep. F. Physiol., Lond. 156, 424-444.

Ebels, I., Balemans, M.G.M. \& VerkLey, A.J. (1972) Separation of pineal extracts on Sephadex G-10. II. A spectro-fluorometric and thin layer chromatographic study of indoles in a sheep pineal extract. F. neuro-visc. Relations 32, 270-281.

Hyyppa, M.T., Cardinali, D.P. \& WuRTMan, R.J. (1973) Sex-dependent increase in pineal hydroxy indole-O-methyltransferase activity after a single intra-ventricular injection of 6-hydroxydopamine to newborn rats. Neuroendocrinology 11, 274-283.

JoRdAN, H.E. (1911) The histogenesis of the pineal body of the sheep. Am. F. Anat. 12, 249-275.

Liggins, G.G., Fairclough, R.J., Grieves, S.A., Kendall, J.Z. \& Knox, B.S. (1974) The mechanism of initiation of parturition in the ewe. Recent Prog. Horm. Res. 29, 111-159.

Reiter, R.J. (1973) Comparative physiology: pineal gland. A. Rev. Physiol. 35, 305-328.

URRY, R., Barfuss, D.W. \& ELLIS, L.C. (1972) Hydroxy indole-O-methyltransferase activity of male rat pineal glands following hypophysectomy and HCG treatment. Biol. Reprod. 6, 238-243. 